\title{
Occupancy and Belt Detection in Removable Vehicle Seats via
}

\section{Inductive Power Transmission}

\author{
Joan Albesa, Member, IEEE and Manel Gasulla, Member, IEEE
}

\begin{abstract}
This work proposes the use of inductive links in order to wirelessly power an autonomous sensor in a vehicle application. The selected application is intended for occupancy and belt detection in removable vehicle seats, where wiring the seat detectors from the vehicle chassis is unpractical. The autonomous sensor includes the seat detectors and a wireless transceiver to transfer the data about the state of the detectors. In order to compensate the loose coupling between the coupled coils, resonant tanks were used. To drive the transmitting resonant network, a commercial class D amplifier was used. Working frequency was restricted to $150 \mathrm{kHz}$. Commercial magnetic-core coils were selected as they provide high coil values and quality factors in a small-size factor, which is a requirement for the intended application. At the receiving network, a rectifier and a voltage regulator were used to provide a DC voltage supply to the autonomous sensor. Three kinds of voltage regulators were compared from the point of view of the power efficiency. Both a theoretical analysis and experimental results are presented for different combinations of coils and working frequencies. Theoretical analysis shows that the operating points for the linear shunt regulator always lead to higher power efficiencies compared to other alternatives such as linear series and switching buck regulators. Experimental tests were carried out using a mechanical setup to fix the coil-to-coil distances. Experimental results agree with the theoretical analysis. Achieved power efficiencies ranged from around $50 \%$ to $10 \%$ for coil-to-coil distances from one to three times the inner diameter of the coils. Experimental tests also showed that the autonomous sensor was properly powered up to coil-to-coil distances of $2.5 \mathrm{~cm}$, i.e. more than four times the inner diameter of the coils.
\end{abstract}

Copyright (c) 2013 IEEE. Personal use of this material is permitted. However, permission to use this material for any other purposes must be obtained from the IEEE by sending a request to pubspermissions@ieee.org.

Joan Albesa is corresponding author. Address: Department of Microsystems Engineering, Albert-Ludwigs-Universitát Freiburg, Germany. E-mail: joan.albesa@imtek.uni-freiburg.de.

Manel Gasulla is with e-CAT group, Department of Electronic Engineering, Universitat Politècnica de Catalunya, Spain. E-mail: manel.gasulla@upc.edu.
Index Terms - Autonomous Sensors, Voltage Regulation, Inductive Power Transfer, Removable Vehicle Seats, Seat Belt, Occupancy Detection.

\section{Introduction}

In some applications, the use of a physical connection between the electronic system to be powered and its power source is disadvantageous or even unfeasible. One solution is to wirelessly transfer energy by using a coupled pair of coils. Both low- and high-power applications have been reported. Lowpower transfer includes biomedical implants [1], [2], [3], RFID systems [4], or portable electronic products [5], [6] whereas high-power transfer includes industrial applications [7], [8] and battery recharging of electrical vehicles [9], [10]. As for vehicles, other foreseen applications include wireless powering sensors installed in rotating parts such as wheels or in removable parts such as seats. As for the wheels, tirepressure monitoring systems (TPMS) are currently powered by primary batteries. However, as the desired target for lifetime of batteries is around 10 years, the use of batteries is challenging. In addition, the final disposition of millions of batteries will create environmental impacts and hazards. As an alternative, an Australian company is offering a battery-less TPMS based on inductive power transfer [11]. As for the seats, some vans and minivans incorporate removable seats in order to flexibly arrange their internal space. Some commercial models incorporate at most a seat belt detector for the removable seats. In order to avoid wiring the seats, a passive detection is performed via an inductive link [12], [13]. Intelligent airbags that incorporate smart seat sensors will be required in order to minimize the risk to infants and children. They should be appropriately deployed depending on whether the passenger is an adult, an infant car seat is present, or the seat is empty. The smart seat sensors or detectors may require power to operate. One option for removable seats, apart from using batteries, is the transmission of power via inductive links from the chassis floor to the seat. Here, this application is tackled. 
Hence, this paper presents a novel application for inductive power links: occupancy and belt detection in removable vehicle seats, where wiring the sensors is unpractical. The application requires powering the autonomous sensor in charge of the detectors and wirelessly transfer the acquired data to a central processing unit. The demanded power consumption is below $90 \mathrm{~mW}$, mainly devoted to the wireless transceiver in charge of the data transmission. As the autonomous sensor requires a fixed DC voltage supply, a rectifier and some kind of voltage regulation are required in the receiving network. This circuit arrangement has been used for powering biomedical implants [1], [14], [15]. Different types of voltage regulators have been used, such as linear shunt and series regulators, and switching regulators. However, their impact on the system power efficiency has not been thoroughly assessed in the literature. Here, a comprehensive analysis on the power performance of commercial regulators used in the receiving network is shown. Analytical derivations and calculations are provided as well as experimental results. With regard to our previous publications [16], [17], [18], the application is more extensively described, the analysis and experimental results are extended with more cases and graphs, and an autonomous sensor with commercial seat detectors is used. The paper is structured as follows: section II presents the selected application, section III presents a generic analysis of the inductive power transmission system, section IV thoroughly analyzes the secondary network, section $\mathrm{V}$ details the circuit implementation, section VI presents the analytical calculations, section VII shows the experimental results, and, finally, section VIII concludes the work. Although this work is focused in a particular application and power range, some of the analytical expressions and reached conclusions are rather general and could be transferred to other application fields that require inductive power transmission.

\section{Seat Occupancy and Belt Detection in Removable Vehicles Seats}

Passive safety systems in vehicles aim to reduce injuries of the occupants in an accident. The use of Seat Belt Reminder (SBR) systems is effective in reminding the vehicle occupants to buckle up and is reported as one of the most effective ways in avoiding deaths and injuries in traffic accidents. SBR systems may also be used for the proper control on the deployment of other passive safety devices such as airbags. Seat occupancy and belt detectors are typically used in SBR systems. Wiring the detectors in removable seats, present in some vehicle models, can be unpractical. In this work we investigate instead the use of inductive links for occupancy and belt detection. Fig. 1 shows a possible configuration of the removable seat, detectors, and coils, where the transmitting (primary) coil is placed on the vehicle floor and the receiving (secondary) coil is attached under the seat. In [13], we used the inductive link for passively inferring the state of the seat detectors. Here, we propose transferring energy from the primary to the secondary network, where an autonomous sensor is capable of adding intelligence to the seat detection process.

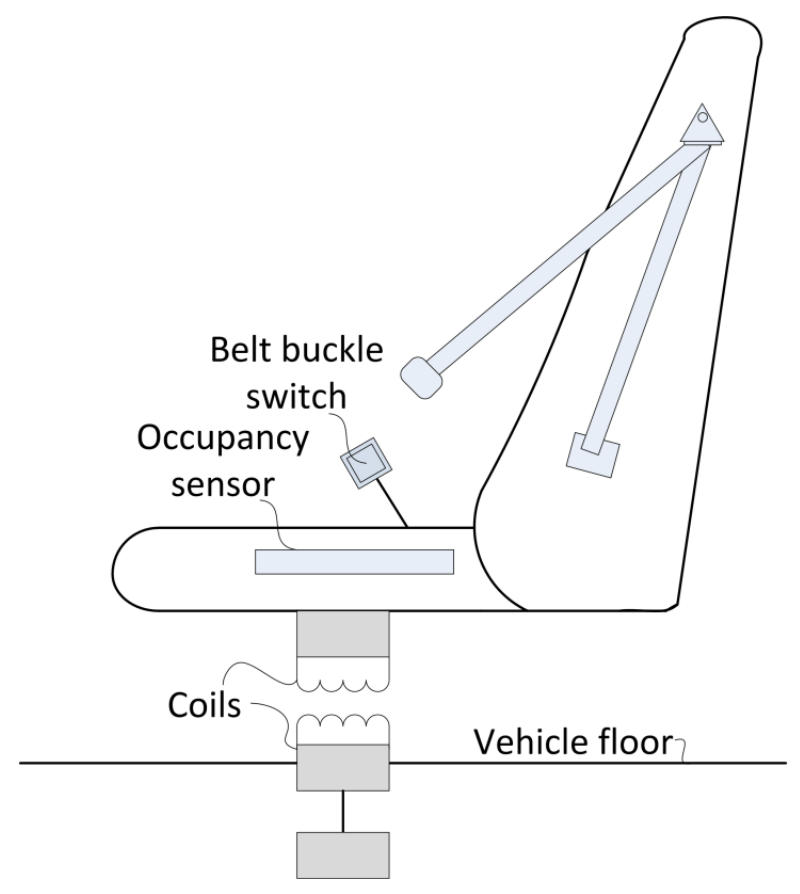

Fig. 1 A possible configuration of the removable seat, detectors, and coils.

For the setup, we used commercial seat detectors. The occupancy detector (IEE company) consists of a flexible sensor mat, which is inserted into the vehicle seat. The mat itself is composed of two sandwiched carrier sheets held together by an adhesive. Increased pressure on the sensor mat causes a large electrical resistance variation, from a very high resistance when the seat is empty to a very low resistance when the seat is occupied. Thus, the sensor can be roughly modeled as a switch (i.e. two states: short- and open-circuit), which allows detecting the presence of a passenger using a simple electronic interface. The seat belt detector (TRW Sabelt) consists of a buckle and the corresponding buckle housing, which can also be modeled as a switch. An unbuckled or buckled up seat belt can be respectively modeled as a short- or opencircuit.

Fig. 2 shows the proposed solution for the autonomous sensor with the seat detectors. An ETRX2 device (Telegesis), which embeds a microcontroller and an RF transceiver, was used to sense the state of 
the detectors and transmit the information wirelessly using the embedded Zigbee stack. Other communication standards such as Bluetooth, more common in vehicles, could be used. Appropriate resistors $\left(R_{\mathrm{a}}\right.$ and $\left.R_{\mathrm{b}}\right)$ were placed in series with the sensors in order to form voltage dividers. Their outputs were respectively connected to the inputs (ADC1 and ADC2) of the ETRX-2 built-in analog-to-digital (ADC) converter.

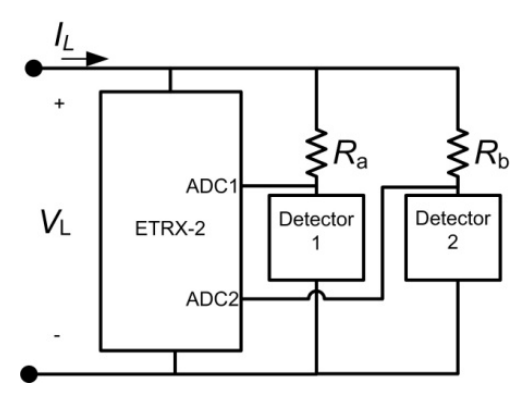

Fig. 2 Schematic circuit of the autonomous sensor.

In Fig. 2, $V_{\mathrm{L}}$, and $I_{\mathrm{L}}$ are respectively the voltage supply and current consumption of the autonomous sensor. $V_{\mathrm{L}}$ is set to $3 \mathrm{~V}$ by the output of a preceding voltage regulator. $I_{\mathrm{L}}$ is maximum when the autonomous sensor is transmitting the data of the sensors and was measured to be $c a .30 \mathrm{~mA}$. So, the equivalent load resistance of the autonomous sensor, $R_{\mathrm{L}}\left(=V_{\mathrm{L}} / I_{\mathrm{L}}\right)$, will be higher than $100 \Omega$ and the associated power consumption, $P_{\mathrm{L}}$, will be lower than $90 \mathrm{~mW}$.

\section{Inductive Power Transmission}

In order to remotely power the autonomous sensor, an inductive link with a couple of coils has been used. Inductive links allow transmitting energy from a primary network to a secondary network using a pair of coupled coils. The power source is located at the primary network whereas the load to be powered is placed at the secondary network. To counteract the loose coupling between the coils, compensation capacitors are used [3], [5], [7]-[10], [16]-[23]. Capacitors can be placed in series or parallel with the coils, leading respectively to series or parallel resonant tanks. Thus, four different topologies result. In [21] and [22], it is shown that the series-series topology is the unique in which the compensation capacitor used in the primary network can be fixed to a constant value independently of the load and of the distance between the coils. This feature is highly attractive for an industrial application because no in-the-field tuning is required. So, the series-series topology has been selected in this work.

Fig. 3 shows the simplified equivalent circuit of a pair of magnetically coupled series resonators, being the left- and right-hand sides the primary and secondary networks, respectively. $V_{1}$ is a sinusoidal signal that models the voltage output of the power source that drives the primary network; $I_{1}$ and $I_{2}$ stand for the currents of the primary and secondary networks; $L_{1}$ and $L_{2}$ model the coils; $C_{1}$ and $C_{2}$ are the compensation capacitors to work at resonance; $R_{\mathrm{s}}$ models the output resistance of the power source, $R_{\mathrm{L} 1}$ and $R_{\mathrm{L} 2}$ model the losses of the coils, and $R_{\mathrm{Load}}$ models the load; and finally $M$ models the mutual inductance between the coils. Here, $R_{\text {Load }}$ comprises not only the autonomous sensor, presented in section II, but also the rectifier and regulator used in order to provide a DC voltage to the autonomous sensor. Details will be provided in section IV. Losses of the coils account for that due to the resistance of the winding wire, including the skin and proximity effects, and core losses. Hereinafter, the parameters of voltage and current are assumed to be root-mean-square values.

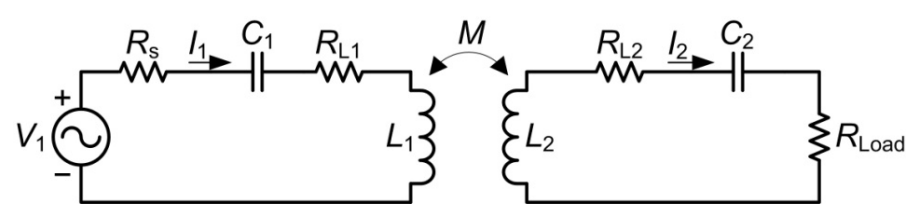

Fig. 3 Equivalent circuit for the series-series topology of an inductive power transmission system.

Compensation capacitors used in the primary and secondary networks are tuned at the same resonance frequency, i.e.

$$
\omega_{r}=\frac{1}{\sqrt{L_{1} C_{1}}}=\frac{1}{\sqrt{L_{2} C_{2}}}
$$

being the power source also tuned at $\omega_{\mathrm{r}}$. Thus, from the analysis of Fig. 3, we obtain

$$
\begin{gathered}
V_{1}=R_{1} I_{1}-j \omega M I_{2} \\
j \omega M I_{1}=R_{2} I_{2}
\end{gathered}
$$

where $R_{1}=R_{\mathrm{S}}+R_{\mathrm{L} 1}, R_{2}=R_{\mathrm{L} 2}+R_{\text {Load. }}$.

The received power at the load ( $\left.R_{\text {Load }}\right)$ is given by [3], [23]

$$
P_{\text {Load }}=\left(\frac{V_{1}}{R_{1}+R_{\mathrm{r}}}\right)^{2} R_{\mathrm{r}} \frac{R_{\text {Load }}}{R_{2}}
$$

where 


$$
R_{r}=\frac{\left(\omega_{\mathrm{r}} M\right)^{2}}{R_{2}}
$$

is the reflected resistance of the secondary onto the primary network.

As the value of $R_{\text {Load }}$ depends on $R_{\mathrm{L}}$ (autonomous sensor) and the kind of rectifier and voltage regulator used, as will be seen later in section IV, it is of interest to assess $P_{\text {Load }}$ in function of $R_{\text {Load. }}$. A maximum of $P_{\text {Load }}$ can be found by solving $\partial P_{\text {Load }} / \partial R_{\text {Load }}=0$, obtaining

$$
\begin{aligned}
P_{\text {Load, } \max }=\frac{V_{1}^{2}}{4 R_{1}} & \frac{(\omega M)^{2}}{R_{1} R_{\mathrm{L} 2}+(\omega M)^{2}} \\
& =\frac{V_{1}^{2}}{4 R_{1}} \frac{k^{2} Q_{1} Q_{\mathrm{L} 2}}{1+k^{2} Q_{1} Q_{\mathrm{L} 2}}
\end{aligned}
$$

where

$$
\begin{gathered}
k=\frac{M}{\sqrt{L_{1} L_{2}}} \\
Q_{1}=\frac{\omega_{\mathrm{r}} L_{1}}{R_{1}}
\end{gathered}
$$

and $Q_{\mathrm{L} 2}$ is the quality factor of the secondary coil and for loosely coupled coils, $k<<1$. For an appropriate operations, the value of $P_{\text {Load,max }}$ must be higher than the power demanded by the autonomous sensor $\left(P_{\mathrm{L}}\right)$.

Finally, the optimum load corresponding to $P_{\text {Load,max }}$ is given by

$$
R_{\mathrm{Load}, \mathrm{opt}}=R_{\mathrm{L} 2}\left(1+k^{2} Q_{1} Q_{\mathrm{L} 2}\right)
$$

\section{Secondary network}

Fig. 4 shows the block schematic of the secondary network when using a rectifier and a voltage regulator in front of the autonomous sensor, where

$$
V_{\mathrm{L}}=I_{\mathrm{L}} R_{\mathrm{L}}
$$

$V_{\text {reg, }} I_{\text {reg }}$ and $R_{\text {reg }}$ are respectively the voltage, current and equivalent resistance at the input of the voltage regulator, being

$$
V_{\text {reg }}=I_{\text {reg }} R_{\text {reg }}
$$

and $R_{\text {Load }}$ is the equivalent resistance seen from the input of the rectifier. $R_{\text {Load }}$ depends on $R_{\text {reg }}$ and the type of rectifier employed. At the same time, $R_{\text {reg }}$ depends on $R_{\mathrm{L}}$ and on the specific type of voltage regulator. Finally, $C_{\mathrm{r}}$ is a filter capacitor.

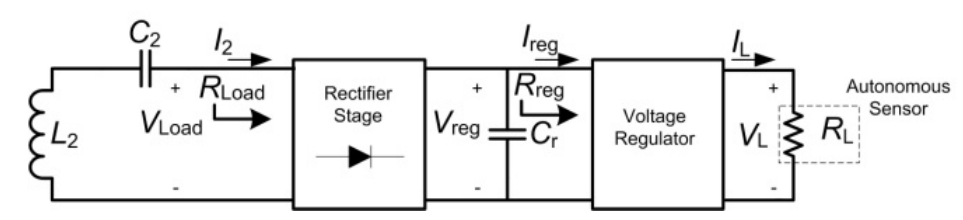

Fig. 4 Block diagram of the secondary network that includes the rectifier and voltage regulator.

As for the regulators, different types are considered: linear shunt and series regulators, and inductor-based switching regulators. These regulators behave respectively as voltage, current and power loads. Below, we present the rectifier and voltage regulation stages. From their analysis we will obtain expressions of $P_{\text {Load }}$ in function of $R_{\text {Load, }}$ which combined with (3) will lead to the determination of the operating points ( $\left.P_{\text {Load }}, R_{\text {Load }}\right)$. The overall efficiency will also be reported.

\section{A. Rectifier Stage}

For a series-resonant secondary tank, the rectifier must allow a sinusoidal input current. Hence, a current-driven rectifier is used [1]. Two different rectifiers are considered: bridge and half-wave (Fig. 5).

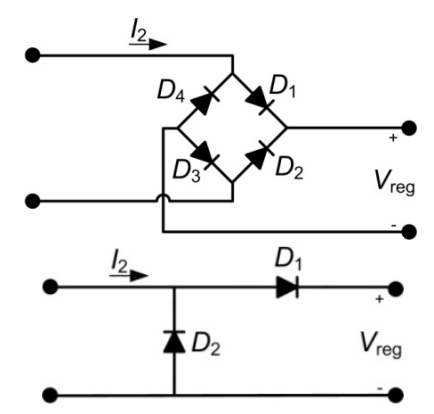

Fig. 5 Current-driven rectifiers: Bridge (left) and halfwave (right).

These rectifiers allow the continuous charge of the filter capacitor $C_{\mathrm{r}}$. In steady-state, the electrical charge injected to $C_{\mathrm{r}}$ through the rectifier must equal to that provided to the ensuing stage, the voltage regulator. Thus, 


$$
I_{2}=\frac{I_{\text {reg }}}{\sqrt{F}}
$$

where $I_{2}$ is the rms value and

$$
F= \begin{cases}\frac{8}{\pi^{2}} & \text { for the bridge rectifier } \\ \frac{2}{\pi^{2}} & \text { for the half-wave } \\ \text { rectifier }\end{cases}
$$

The equivalent $P_{\text {Load }}$ can be expressed as

$$
P_{\text {Load }}=I_{2}^{2} R_{\text {Load }}
$$

and also as

$$
P_{\text {Load }}=P_{\mathrm{D}}+P_{\text {reg }}
$$

where in both rectifiers

$$
P_{\mathrm{D}}=2 V_{\mathrm{D}} I_{\text {reg }}
$$

is the power dissipated by the rectifier, being $V_{\mathrm{D}}$ the forward voltage drop of one diode (assumed constant), and

$$
P_{\text {reg }}=V_{\text {reg }} I_{\text {reg }}
$$

is the power dissipated by the regulator plus that consumed by the autonomous sensor. Thus, equating (13) with (14) and operating with some of the remaining expressions from (10) to (16), we get

$$
R_{\text {Load }}=F\left(1+\frac{2 V_{\mathrm{D}}}{V_{\text {reg }}}\right) R_{\text {reg }}
$$

where the equivalency only applies to the amount of power drawn from the secondary resonant tank [1].

\section{B. Linear Shunt Regulator}

The linear shunt voltage regulator is disposed just across the power supply rail $\left(V_{\mathrm{L}}\right)$ of the autonomous sensor $\left(R_{\mathrm{L}}\right)$. In this case, $V_{\mathrm{L}}=V_{\text {reg. }}$. Whenever $V_{\text {reg }}$ in Fig. 4 is lower than the shunt voltage $\left(V_{\mathrm{Z}}\right)$, the shunt regulator acts as an open circuit. Thus, $R_{\text {reg }}=R_{\mathrm{L}}$.
Otherwise, it acts as a constant voltage load by clamping the voltage $V_{\text {reg }}\left(=V_{\mathrm{L}}\right)$ to $V_{\mathrm{Z}}$. In this case, $R_{\text {reg }}$ $=R_{\mathrm{L}} \| R_{\mathrm{Z}}$, where $R_{\mathrm{Z}}$ is the equivalent resistance offered by the shunt regulator. Thus, as $R_{\text {reg }} \leq R_{\mathrm{L}}$, and assuming $V_{\text {reg }}=V_{\mathrm{Z}}$, from (17) we find the maximum value of $R_{\text {Load }}$ as

$$
R_{\text {Load,max }}=F\left(1+\frac{2 V_{\mathrm{D}}}{V_{\mathrm{Z}}}\right) R_{\mathrm{L}}
$$

where $V_{\mathrm{D}}$ and $V_{\mathrm{Z}}$ are known parameters. On the other hand, from (11) and (13) we get

$$
I_{\text {reg }}=\sqrt{F \frac{P_{\text {Load }}}{R_{\text {Load }}}}
$$

and substituting (19) in (14) and operating, we obtain

$$
P_{\text {Load }}=F \frac{\left(2 V_{\mathrm{D}}+V_{\mathrm{Z}}\right)^{2}}{R_{\mathrm{Load}}}
$$

\section{Linear Series Regulator}

A linear series regulator fixes a desired output voltage $V_{\mathrm{L}}$ requiring at the same time $V_{\text {reg }} \geq V_{\mathrm{L}}$. On the other hand, involved currents are related by

$$
I_{\text {reg }}=I_{\mathrm{L}}+I_{\text {leak }}
$$

where $I_{\text {leak }}$ is the leakage current of the series regulator and $I_{\mathrm{L}}$ is given by (9). Thus, assuming $I_{\mathrm{L}}$ and $I_{\text {leak }}$ as constant values, the voltage regulator acts as a constant current load.

Operating from (9), (10) and (21) we get

$$
R_{\text {reg }}=\frac{V_{\text {reg }}}{V_{\mathrm{L}}} \frac{1}{1+\frac{I_{\text {leak }}}{I_{\mathrm{L}}}} R_{\mathrm{L}}
$$

The minimum value of $R_{\text {reg }}$ will be found at $V_{\text {reg }}=V_{\mathrm{L}}$. Then, from (17) we obtain the minimum value of $R_{\text {Load, }}$

$$
R_{\text {Load,min }}=F\left(1+\frac{2 V_{\mathrm{D}}}{V_{\mathrm{L}}}\right) \frac{1}{1+\frac{I_{\text {leak }}}{I_{\mathrm{L}}}} R_{\mathrm{L}}
$$

On the other hand, by substituting (21) in (11) and the resulting expression in (13), $P_{\text {Load }}$ can be expressed as 


$$
P_{\text {Load }}=\frac{\left(I_{L}+I_{\text {leak }}\right)^{2}}{F} R_{\text {Load }}
$$

\section{Switching Buck Regulator}

The same as the linear series regulator, a switching buck regulator fixes a desired output voltage $V_{\mathrm{L}}$ and requires $V_{\text {reg }} \geq V_{\mathrm{L}}$. On the other hand, the input and output power of the switching buck regulator are related by

$$
P_{\mathrm{L}}=\eta P_{\text {reg }}
$$

where $\eta$ is the efficiency of the regulator. Assuming a constant value of $\eta$, the switching regulator acts as a constant power load. Efficiencies higher than $90 \%$ are easily achieved with commercial devices. Operating from (9), (10) and (25) we get

$$
R_{\text {reg }}=\left(\frac{V_{\text {reg }}}{V_{\mathrm{L}}}\right)^{2} \eta R_{\mathrm{L}}
$$

Again, the minimum value of $R_{\text {reg }}$ will be achieved at $V_{\text {reg }}=V_{\mathrm{L}}$. Then, from (17) we obtain

$$
R_{\text {Load,min }}=F\left(1+\frac{2 V_{\mathrm{D}}}{V_{\mathrm{L}}}\right) \eta R_{\mathrm{L}}
$$

On the other hand, by using (15) and (25) in (14), $P_{\text {Load }}$ can be expressed as

$$
P_{\text {Load }}=\frac{P_{\mathrm{L}}}{\eta}+2 V_{\mathrm{D}} I_{\mathrm{reg}}
$$

and substituting (19) in (28) we get

$$
P_{\text {Load }}=\frac{P_{\mathrm{L}}}{\eta}+2 V_{\mathrm{D}} \sqrt{F \frac{P_{\text {Load }}}{R_{\text {Load }}}}
$$

Further processing we obtain

$$
P_{\text {Load }}=\frac{P_{\mathrm{L}}}{\eta}+\frac{2 V_{\mathrm{D}}\left(V_{\mathrm{D}} F+\sqrt{\left.\left(V_{\mathrm{D}} F\right)^{2}+R_{\text {Load }} \frac{P_{\mathrm{L}} F}{\eta}\right)}\right.}{R_{\text {Load }}}
$$

The operating points ( $\left.P_{\text {Load }}, R_{\text {Load }}\right)$ can be obtained by combining (3) with (20), (24) and (30). Previously, the values of the different parameters must be known, which depends on the specific circuit implementation. Section V presents the details.

\section{E. System Efficiency}

System efficiency can be expressed as

$$
\eta_{\mathrm{T}}=\frac{P_{\mathrm{L}}}{P_{\mathrm{g}}}
$$

where $P_{\mathrm{g}}$ refers to the generated power by the power source and is given by

$$
P_{\mathrm{g}}=\frac{V_{1}^{2}}{R_{1}+R_{\mathrm{r}}}
$$

Substituting (32) in (31), we get

$$
\eta_{\mathrm{T}}=\frac{P_{\mathrm{L}}}{V_{1}^{2}}\left(R_{1}+R_{r}\right)
$$

For fixed values of $P_{\mathrm{L}}$ and $V_{1}$, efficiency increases for larger values of $R_{1}$ and $R_{\mathrm{r}}$. However, from (5), larger values of $R_{1}$ lead to a lower value of $P_{\text {Load,max, }}$ which can result in the inability to power the load. On the other hand, a higher value of $R_{\mathrm{r}}$ can be achieved, from (4), at shorter distances between the coupled coils ( $M$ increases) or for lower values of $R_{\text {Load }}$ and thus of $R_{2}$. The value of $R_{\text {Load }}$ will be given by the operating point, which will depend, in part, on the specific type of regulator used. As will be seen in Section VI, this issue will be determinant in order to choose the best regulator type in terms of system efficiency.

\section{Circuit implementation}

A rather low frequency of operation $(<150 \mathrm{kHz})$ was selected for two reasons: 1) to better comply with the reference levels for general public exposure to time-varying electric and magnetic fields issued by the ICNIRP [24], and 2) to reduce the circuit complexity and power losses of the power amplifier.

Based on these premises, Fig. 6 shows the circuit schematic of the implemented primary network. This circuit was previously presented in [18] and [25]. It is mainly composed of a class $\mathrm{D}$ power amplifier based on a low-cost commercial self-oscillating half-bridge driver (IR2153) and two external N-channel MOSFETs (BSH103, Philips Semiconductor), $M_{\mathrm{a}}$ and $M_{\mathrm{b}}$. The driver, powered at $12 \mathrm{~V} \mathrm{DC}$ (battery voltage in vehicles), alternatively activates the two MOSFETs, thus injecting a square wave signal into the resonant network. The operating frequency, fixed by the $R_{\mathrm{b}} C_{\mathrm{b}}$ 
network, can be finely tuned, using a multi-turn potentiometer for $R_{\mathrm{b}}$, to the resonant frequency of the series resonant tank $L_{1} C_{1}$.

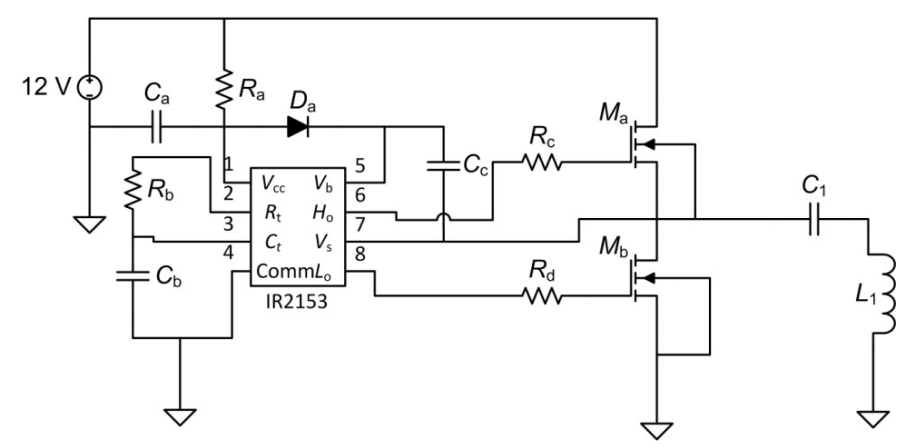

Fig. 6 Schematic circuit of the primary network.

For moderate to high quality factors, only the first voltage harmonic ( $V_{1}$ in Fig. 3) will generate a (sinusoidal) current through the network, being its theoretical amplitude of $7.64 \mathrm{~V}\left(2 V_{\mathrm{cc}} / \pi\right)$ and its rms value $\left(V_{1}\right)$ of $5.4 \mathrm{~V}$. The MOSFET manufacturer publishes an $\mathrm{ON}$ resistance $\left(R_{\mathrm{s}}\right.$ in Fig. 1) of $0.4 \Omega$ (@) $V_{\mathrm{GS}}=2.5 \mathrm{~V}$ ).

As for the secondary network (Fig. 4), we used shottky diodes (BAT47 model) for the rectifiers and the following commercial devices for the regulators in order to achieve $V_{\mathrm{L}}=3 \mathrm{~V}$ : TL431 (shunt regulator), LP2980 (series regulator) and LTC1877 (switching buck regulator).

A high enough value of $P_{\text {Load }}$ has to be achieved in order to power the autonomous sensor. From (5), higher values of $P_{\text {Load,max }}$ can be achieved by increasing $k, Q_{1}$ and $Q_{\mathrm{L} 2}$. As for the primary coil, a high value of $Q_{1}$ implies both a high coil value and quality factor $\left(Q_{\mathrm{L} 1}\right)$. On the other hand, the use of small-size coils is a requirement in the selected application. As a result, and considering a low frequency of operation $(<150$ $\mathrm{kHz}$ ), magnetic-core coils are good candidates to fulfill all the requirements as they provide both high coupling and quality factors, as well as high coil values [13], [25]. Magnetic-core coils from Fastron (PIST model) were selected. As for the coil values, we preliminary selected the first value of each decade provided by the manufacturer and covered the full available range, i.e. $10 \mu \mathrm{H}, 100 \mu \mathrm{H}, 1 \mathrm{mH}$, and $10 \mathrm{mH}$. First, their resistance was measured at several frequencies. In order to obtain the resistance values, we used a seriesresonant network and measured the resistance at the resonant frequency by using an HP4294A impedance analyzer. Appropriate values of capacitors were used in order to tune different resonant frequencies within the range from $1 \mathrm{kHz}$ to $150 \mathrm{kHz}$. Then, the quality factors were inferred by using the measured resistances and the nominal values of the inductances. Fig. 7 shows the results. A maximum was achieved around $40 \mathrm{kHz}$ for $100 \mu \mathrm{H}$ and $1 \mathrm{mH}$. For the other two coils, $10 \mu \mathrm{H}$ and $10 \mathrm{mH}$, the maximum value was achieved at the highest tested frequency, approximately 120 $\mathrm{kHz}$. On the other hand, the achieved maximum value at a given frequency increased with an increase of the coil value. So, only the highest two coil values, $1 \mathrm{mH}$ and $10 \mathrm{mH}$, were finally selected as they offer both high coil values and quality factors.

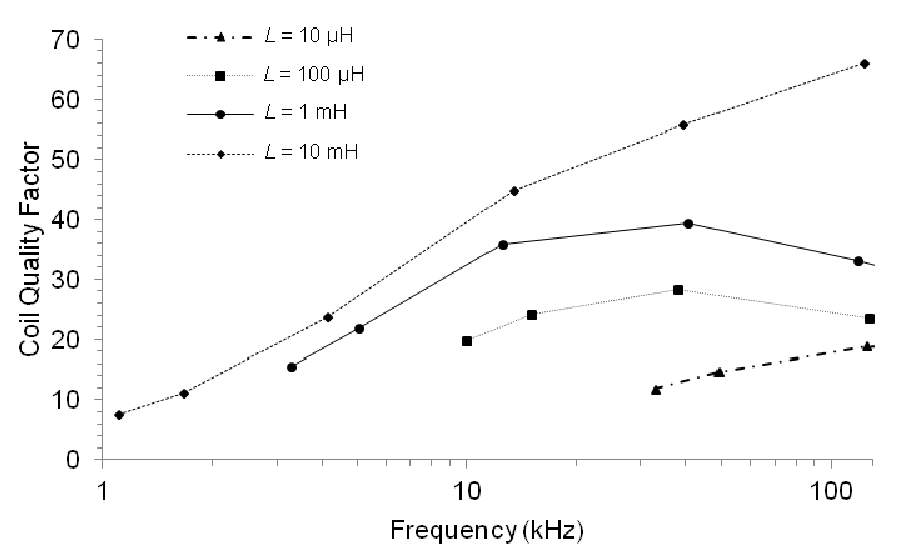

Fig. 7 Values of the resulting quality factors for the Fastron commercial coils.

\section{Analytical Calculations}

In order to analytically obtain the operating points ( $\left.P_{\text {Load, }}, R_{\text {Load }}\right)$ we combined (3) with (20), (24) and (30), and solved the resulting expression with the MAPLE software. As for (3), we carried out calculations from $d$ $=0.5 \mathrm{~cm}$ to $d=2.5 \mathrm{~cm}$ in steps of $0.5 \mathrm{~cm}$. This corresponds approximately to a distance range between one and four times the inner diameter of the selected coils $(0.6 \mathrm{~cm})$. The parameter values used for the calculations are shown in Table 1, some of which have been previously reported. As can be seen, we used different combinations of coils and two resonant frequencies $(40 \mathrm{kHz}$ and $120 \mathrm{kHz}$ ), which lead to five cases. The values of $k$ were taken from the simulations of the ferrite-core coils presented in [13], [16]; resistance values of the coils were measured as described in section $\mathrm{V}$; and $R_{1}$ was found as the addition of $R_{\mathrm{S}}$ and $R_{\mathrm{L} 1}$, where a value of $1 \Omega$ was considered for $R_{\mathrm{s}}$. To emulate the autonomous sensors, we selected $R_{\mathrm{L}}=100 \Omega$, which corresponds to the case with the highest demanded power consumption (90 $\mathrm{mW})$. The values of $V_{\mathrm{D}}, I_{\text {leak }}$ and $\eta$ were based on the manufacturer datasheets of the regulators, and the values of $V_{\mathrm{Z}}$ and $V_{\mathrm{L}}$ were assumed as $3 \mathrm{~V}$. As for the rectifier, we considered the two types presented in Fig. 5.

Table 1 Values of the parameters used for calculations. 


\begin{tabular}{|c|c|c|c|c|c|c|}
\hline \multicolumn{2}{|c|}{ Parameters } & Case 1 & Case 2 & Case 3 & Case 4 & Case 5 \\
\hline \multicolumn{2}{|l|}{$f_{\mathrm{r}}$} & \multicolumn{3}{|c|}{$40 \mathrm{kHz}$} & \multicolumn{2}{|c|}{$120 \mathrm{kHz}$} \\
\hline \multicolumn{2}{|l|}{$V_{1}$} & \multicolumn{5}{|c|}{$5.4 \mathrm{~V}$} \\
\hline \multicolumn{2}{|c|}{$\begin{array}{l}k @ \mathrm{~d}=0.5,1, \\
1.5,2,2.5,3 \mathrm{~cm}\end{array}$} & \multicolumn{5}{|c|}{$0.125,0.061,0.033,0.019,0.012,0.009$} \\
\hline \multirow{2}{*}{$\begin{array}{c}\text { Coil } \\
\text { inductance }\end{array}$} & $L_{1}$ & \multicolumn{2}{|c|}{$1 \mathrm{mH}$} & $10 \mathrm{mH}$ & \multicolumn{2}{|c|}{$1 \mathrm{mH}$} \\
\hline & $L_{2}$ & $1 \mathrm{mH}$ & $10 \mathrm{mH}$ & \multicolumn{2}{|c|}{$1 \mathrm{mH}$} & $10 \mathrm{mH}$ \\
\hline \multirow{2}{*}{$\begin{array}{l}\text { Coil } \\
\text { resistance }\end{array}$} & $R_{\mathrm{L} 1}$ & \multicolumn{2}{|c|}{$6.45 \Omega$} & $44 \Omega$ & \multicolumn{2}{|c|}{$22 \Omega$} \\
\hline & $R_{\mathrm{L} 2}$ & $6.45 \Omega$ & $44 \Omega$ & $6.45 \Omega$ & $22 \Omega$ & $117 \Omega$ \\
\hline \multicolumn{2}{|l|}{$R_{1}$} & \multicolumn{2}{|c|}{$7.45 \Omega$} & $45 \Omega$ & \multicolumn{2}{|c|}{$23 \Omega$} \\
\hline \multicolumn{2}{|l|}{$R_{\mathrm{L}}$} & \multicolumn{5}{|c|}{$100 \Omega$} \\
\hline \multicolumn{2}{|c|}{$V_{\mathrm{D}}, V_{\mathrm{Z}}, V_{\mathrm{L}}$} & \multicolumn{5}{|c|}{$0.4 \mathrm{~V}, 3 \mathrm{~V}, 3 \mathrm{~V}$} \\
\hline \multicolumn{2}{|c|}{$I_{\text {leak (lineal series) }}$} & \multicolumn{5}{|c|}{$500 \mu \mathrm{A}$} \\
\hline \multicolumn{2}{|c|}{$\eta$ (switching buck) } & \multicolumn{5}{|c|}{0.90} \\
\hline
\end{tabular}

Table 2 shows, as an illustrative example, the calculated values of $R_{\text {Load }}$ for case 2 when using the bridge rectifier. $R_{\mathrm{r}}, P_{\mathrm{g}}$ and $\eta_{\mathrm{T}}$ are also shown and were inferred from (4), (32) and (33), respectively. As can be seen, the shunt regulator provides the lowest values of $R_{\text {Load }}$ at all the distances, which translates in the highest values of $R_{\mathrm{r}}$ and thus, from (33), leads to the highest values of $\eta_{\mathrm{T}}$. Contrariwise, the buck regulator provides the highest values of $R_{\text {Load }}$ and thus the lowest values of $\eta_{\mathrm{T}}$. The same happens in the rest of cases, as will be shown later, and for both types of rectifiers. At the shortest represented distance, i.e. $0.5 \mathrm{~cm}$, large differences in $\eta_{\mathrm{T}}$ are found and range from $31 \%$ for the shunt regulator to merely a $2.3 \%$ for the buck converter. This means that $0.29 \mathrm{~W}$ has to be sourced $\left(P_{\mathrm{g}}\right)$ when using a shunt regulator whereas a buck converter would require up to $3.9 \mathrm{~W}$. At the largest distances, the values of $R_{\mathrm{r}}$ become very small compared to $R_{1}$ for all the regulators. Thus, $\eta_{\mathrm{T}}$ also becomes very small and $P_{\mathrm{g}}$ needs to be very high. The power is mainly wasted at the transmitting network, which creates a power stress in the components.
Table 2 Calculated values of $R_{\text {Load }}$ and related parameters for the operating points of case 2 when using the bridge rectifier.

\begin{tabular}{|c|c|c|c|c|c|}
\hline $\begin{array}{c}d \\
(\mathbf{c m}) \\
\end{array}$ & Regulator & $\begin{array}{c}\boldsymbol{R}_{\text {Load }} \\
(\boldsymbol{\Omega}) \\
\end{array}$ & $R_{\mathrm{r}}(\Omega)$ & $P_{\mathrm{g}}(\mathrm{W})$ & $\begin{array}{c}y_{\mathrm{T}} \\
(\%) \\
\end{array}$ \\
\hline \multirow{3}{*}{0.5} & Shunt & 70.3 & 92 & 0.29 & 31 \\
\hline & Series & 738 & 13 & 1.4 & 6.5 \\
\hline & S. Buck & $51.8 \mathrm{k}$ & 0.21 & 3.9 & 2.3 \\
\hline \multirow{3}{*}{1} & Shunt & 39.3 & 29 & 0.82 & 11 \\
\hline & Series & 687 & 3.4 & 2.7 & 3.3 \\
\hline & S. Buck & $119 \mathrm{k}$ & 0.21 & 3.9 & 2.3 \\
\hline \multirow{3}{*}{1.5} & Shunt & 30.1 & 9.9 & 1.7 & 5.3 \\
\hline & Series & 437 & 1.5 & 3.2 & 2.8 \\
\hline & S. Buck & 342 & 0.22 & 3.9 & 2.3 \\
\hline \multirow{3}{*}{2} & Shunt & 33.4 & 3.1 & 2.8 & 3.2 \\
\hline & Series & 256 & 0.80 & 3.6 & 2.5 \\
\hline & S. Buck & $1.02 \mathrm{k}$ & 0.23 & 3.9 & 2.3 \\
\hline \multirow{3}{*}{2.5} & Shunt & 52.9 & 0.99 & 3.5 & 2.6 \\
\hline & Series & 153 & 0.48 & 3.7 & 2.4 \\
\hline & S. Buck & 320 & 0.26 & 3.9 & 2.3 \\
\hline
\end{tabular}

In order to better grasp why the shunt regulator provides the lowest values of $R_{\text {Load }}$ and thus the best efficiencies we graphed $P_{\text {Load }}$ versus $R_{\text {Load }}$ for the five cases of Table 1 with the bridge rectifier. Eq. (3) is represented for the previously selected distances. The curves corresponding to (20), (24), and (30) are also represented from the corresponding limiting values of $R_{\text {Load, }}$ which were found from (18), (23) and (27), respectively. The respective limiting values of $R_{\text {Load }}$ are $102.7 \Omega, 100.9 \Omega$ and $92.4 \Omega$ and the corresponding values of $P_{\text {Load }}$ are $113.9 \mathrm{~mW}, 115 \mathrm{~mW}$ and $126.5 \mathrm{~mW}$. The operating points, which correspond to the intersection of (3) at the different distances with (20), (24), and (30), are marked with symbols.

Fig. 8 shows the results for case 1. All the regulators provide three operating points at the distances from $d=0.5 \mathrm{~cm}$ to $d=1.5 \mathrm{~cm}$. As can be 
seen, the shunt regulator provides the lowest values of $R_{\text {Load }}$ at all that distances and thus the highest values of $\eta_{\mathrm{T}}$, whereas the buck regulator provides the highest values of $R_{\text {Load }}$ and thus the lowest values of $\eta_{\mathrm{T}}$. The same happens in the rest of cases, as can be seen in Fig. 9 to Fig. 12.

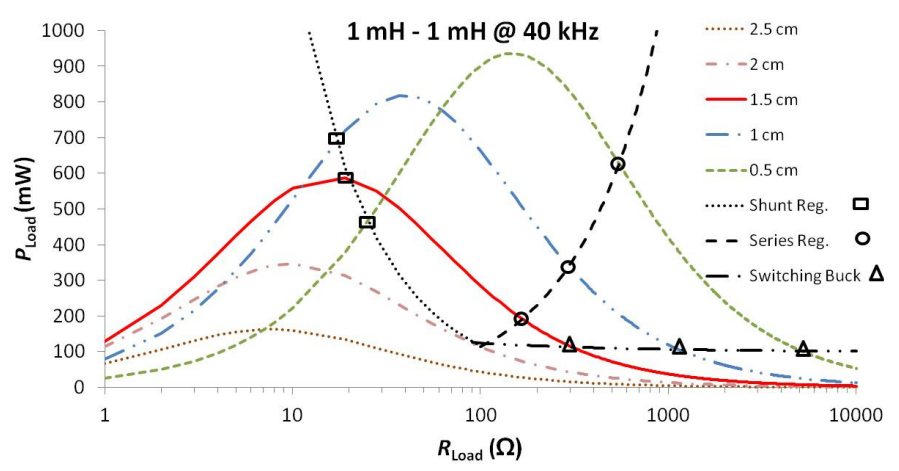

Fig. $8 P_{\text {Load }}$ Vs $R_{\text {Load }}$ for the three types of regulators at different distances (case 1, bridge rectifier).

Fig. 9 shows case 2 in Table 1. With respect to case $1, L_{2}$ increases from $1 \mathrm{mH}$ to $10 \mathrm{mH}$. This leads to a higher value of $Q_{\mathrm{L} 2}$ (see Fig. 7) and, from (5), to a higher value of $P_{\text {Load,max., }}$ specially at the largest distances. $R_{\mathrm{L} 2}$ also increases (see Table 1 ) and so does, from (8), $R_{\text {Load,opt. }}$ Overall, more operating points are achieved.

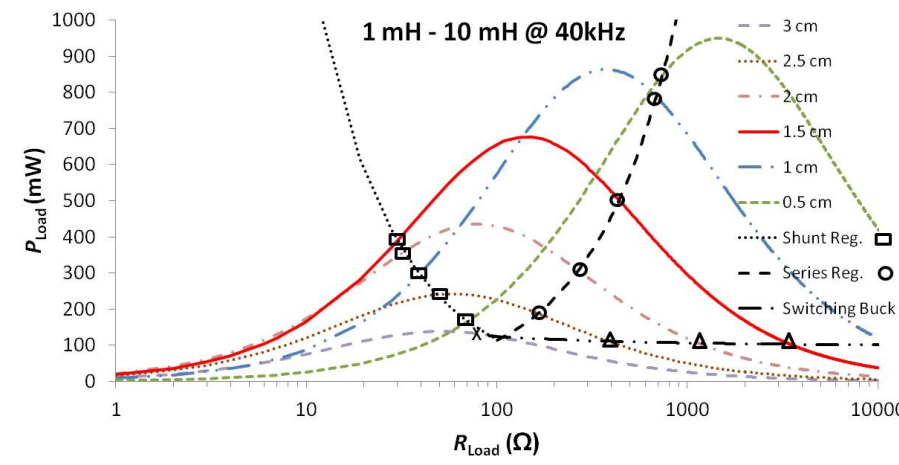

Fig. $9 P_{\text {Load }}$ vs $R_{\text {Load }}$ for the three types of regulators at different distances (case 2, bridge rectifier).

Fig. 10 shows case 3 in Table 1 . With respect to case $1, L_{1}$ increases from $1 \mathrm{mH}$ to $10 \mathrm{mH}$. This leads to an increase of $Q_{\mathrm{L} 1}$ but to a large increase of $R_{\mathrm{L} 1}$ and thus of $R_{1}$. Overall, from (5), a large decrease of $P_{\text {Load,max }}$ is observed. From (8), $R_{\text {Load,opt }}$ slightly increases because of the increase of $Q_{\mathrm{L} 1}$. Now, only two operating points are achieved at $d=0.5 \mathrm{~cm}$ and $d$ $=1 \mathrm{~cm}$.

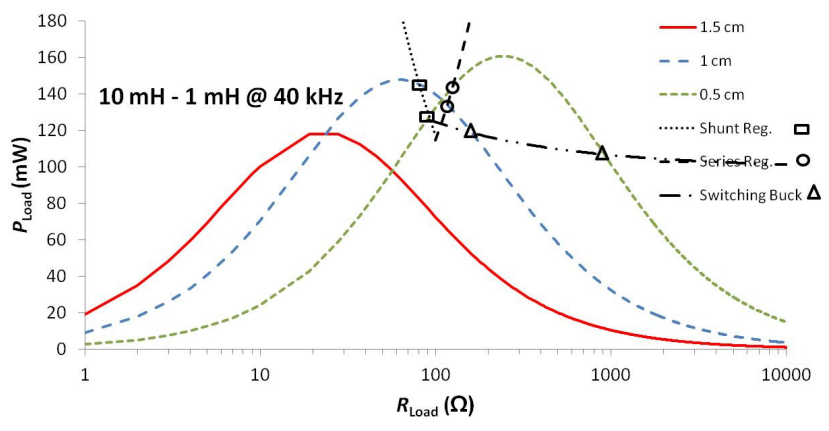

Fig. $10 P_{\text {Load }}$ vs $R_{\text {Load }}$ for the three types of regulators at different distances (case 3, bridge rectifier).

Fig. 11 shows case 4 in Table 1 . With respect to case 1 , the resonant frequency is increased from 40 $\mathrm{kHz}$ to $120 \mathrm{kHz}$. An increase of frequency leads to an increase of the coil resistances and to a decrease of the quality factors. From (5), this means a decrease of $P_{\text {Load,max }}$. The increase of $R_{\mathrm{L} 2}$ leads, from (8), to an increase of $R_{\text {Load,opt. }}$ The same as case 1 , three operating points are provided by the regulators, from $d$ $=0.5 \mathrm{~cm}$ to $d=1.5 \mathrm{~cm}$.

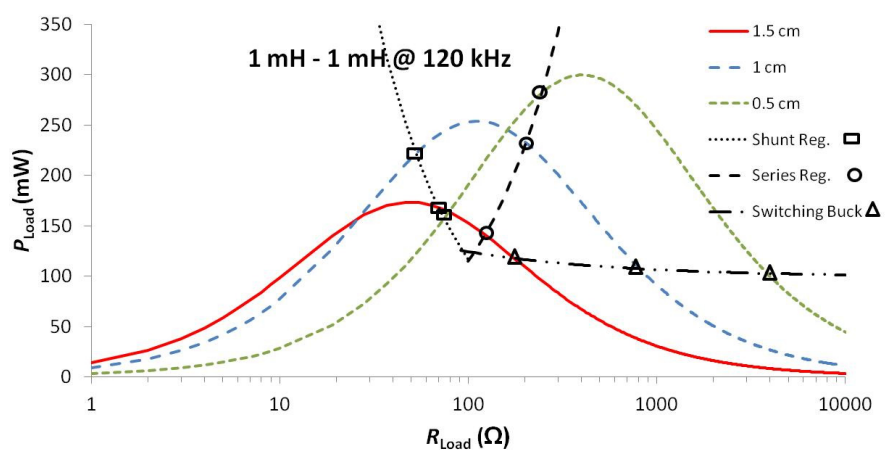

Fig. $11 P_{\text {Load }}$ vs $R_{\text {Load }}$ for the three types of regulators at different distances (case 4, bridge rectifier).

Fig. 12 shows case 5 in Table 1 . With respect to case $4, L_{2}$ increases from $1 \mathrm{mH}$ to $10 \mathrm{mH}$. This leads to a large increase of $Q_{\mathrm{L} 2}$ and, from (5), to a higher value of $P_{\text {Load,max }}$, specially at the largest distances. $R_{\mathrm{L} 2}$ also increases and so does, from (8), $R_{\text {Load,opt. With respect }}$ to case 2 , the resonant frequency is increased from 40 $\mathrm{kHz}$ to $120 \mathrm{kHz}$, which leads to an increase of the coil resistances. As for the coil quality factors, $Q_{\mathrm{L} 1}$ decreases whereas $Q_{\mathrm{L} 2}$ increases. Overall, $P_{\mathrm{Load}, \max }$ decreases. In this case, four operating points are found for the switching buck regulator, from $d=0.5 \mathrm{~cm}$ to $d$ $=2 \mathrm{~cm}$, whereas only two are found for the linear regulators, $d=1.5 \mathrm{~cm}$ and $d=2 \mathrm{~cm}$. 


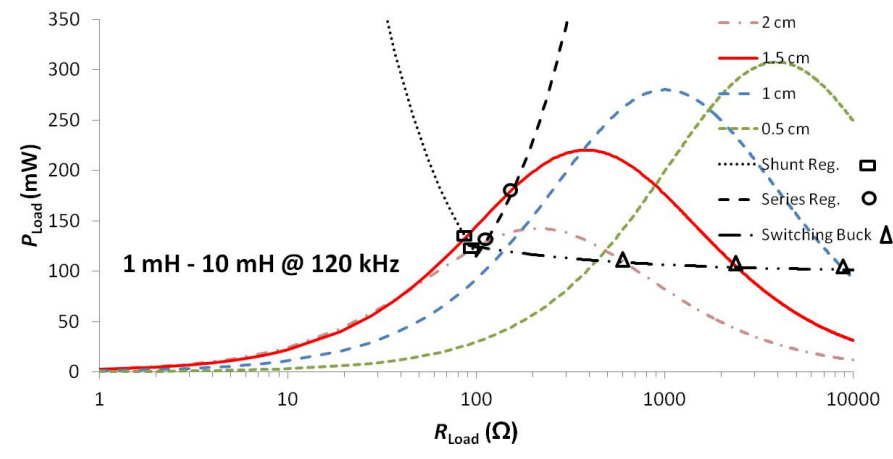

Fig. $12 P_{\text {Load }}$ vs $R_{\text {Load }}$ for the three types of regulators at different distances (case 5, bridge rectifier).

Graphs for the five cases of proposed in Table 1 with the half-wave rectifier are not shown but again the shunt regulator achieves the best results with the exception of case 5, where no operating point exists. In this last case, only the buck regulator provides operating points.

Table 3 provides the values of $\eta_{\mathrm{T}}$ for the shunt regulator (the best type) and for the five cases proposed in Table 1. For each case and distance, two results are shown separated by a slash (/), corresponding the left- and right-side values to the bridge and half-wave rectifiers, respectively. A cross mark $(\mathrm{X})$ indicates that no operating point exists. As for the bridge rectifier, case 2 can operate at all the distances and offers a relative high value of $\eta_{\mathrm{T}}$ at short distances. Case 3 provides the highest value of $\eta_{\mathrm{T}}$ at $d$ $=0.5 \mathrm{~cm}$ but only two operating points, $d=0.5 \mathrm{~cm}$ and $d=1 \mathrm{~cm}$, are possible. Case 5 provides relative high efficiencies at long distances but operation at short distances is not possible. As for the half-wave rectifier, at short distances $(d=0.5 \mathrm{~cm})$, except for case 1 , is not possible to operate. Case 5 offers no operating points, as previously commented. Efficiencies of case 3 at $d=$ $1 \mathrm{~cm}$ and $1.5 \mathrm{~cm}$ are remarkable.
Table 3 Calculated values of $\eta_{\mathrm{T}}$ (in percentage) for the shunt regulator when using a bridge (left) or half-wave (right) rectifier.

\begin{tabular}{|c|c|c|c|c|c|}
\hline $\boldsymbol{d}(\mathbf{c m})$ & Case 1 & Case 2 & Case 3 & Case 4 & Case 5 \\
\hline 0.5 & $13 / 20$ & $31 / \mathrm{X}$ & $46 / \mathrm{X}$ & $35 / \mathrm{X}$ & $\mathrm{X} / \mathrm{X}$ \\
\hline 1 & $5.5 / 7.8$ & $11 / 14$ & $22 / 38$ & $16 / 21$ & $\mathrm{X} / \mathrm{X}$ \\
\hline 1.5 & $3.1 / 3.4$ & $5.3 / 6.2$ & $\mathrm{X} / 25$ & $\begin{array}{c}9.1 / \\
12\end{array}$ & $16 / \mathrm{X}$ \\
\hline 2 & $\mathrm{X} / 2.7$ & $3.2 / 3.6$ & $\mathrm{X} / \mathrm{X}$ & $\mathrm{X} / \mathrm{X}$ & $9.9 / \mathrm{X}$ \\
\hline 2.5 & $\mathrm{X} / 2.4$ & $2.6 / 2.8$ & $\mathrm{X} / \mathrm{X}$ & $\mathrm{X} / \mathrm{X}$ & $\mathrm{X} / \mathrm{X}$ \\
\hline
\end{tabular}

\section{Experimental Results}

The mechanical setup shown in Fig. 13 was used to fix the distance between the coils. The circuits of Fig. 4 and Fig. 6 were used with the components reported in section $\mathrm{V}$. A value of $100 \Omega$ was used to emulate the autonomous sensor.

The procedure to work at the resonance frequency was the following. First, the frequency of the power source was adjusted to the resonant frequency of the primary resonant tank by maximizing its circulating current, which was measured by a Hall effect current probe (Tektronix TCPA 300). Then, the secondary network was tuned by adjusting a suitable value of $C_{2}$. Discrete components were used and a capacitor trimmer was added when necessary.

We first checked the performance of case 2 when using a bridge rectifier and verified that the shunt regulator achieved the best efficiencies, as predicted by the calculations. In order to operate around $40 \mathrm{kHz}$, we selected capacitors of nominal values $C_{1}=15 \mathrm{nF}$ and $C_{2}=1.5 \mathrm{nF}$. Experimental values of $R_{\mathrm{r}}$ (not shown) were inferred from the measurement of the current of the primary resonant tank. Then, $\eta_{\mathrm{T}}$ was inferred from (33).

Overall efficiencies were also estimated for cases 3 and 5 when using the shunt regulator. The selected capacitance values were $C_{1}=1.5 \mathrm{nF}$ and $C_{2}=15 \mathrm{nF}$ for case 3 , and $C_{1}=1.66 \mathrm{nF}$ and $C_{2}=164 \mathrm{pF}$ for case 5. Table 4 shows the results obtained with the bridge (left-side value) and half-wave (right-side value) rectifiers. The results mainly agree with the respective calculated values of Table 3 . The same as when using a bridge rectifier, case 3 offers the highest efficiencies at $d=0.5 \mathrm{~cm}$ and $1 \mathrm{~cm}$ whereas case 5 is the best alternative for $d=1.5 \mathrm{~cm}$ and $2 \mathrm{~cm}$. As for the half- 
wave rectifier, case 3 offers higher efficiencies than those of the bridge rectifier for $d=1 \mathrm{~cm}$ and $1.5 \mathrm{~cm}$.

Table 4 Experimental values of $\eta_{\mathrm{T}}$ (in percentage) for the shunt regulator when using a bridge (left) or half-wave (right) rectifier.

\begin{tabular}{|c|c|c|c|}
\hline $\boldsymbol{d}(\mathbf{c m}) / \boldsymbol{\eta}_{\mathrm{T}}$ & Case 2 & Case 3 & Case 5 \\
\hline 0.5 & $28 / \mathrm{X}$ & $51 / \mathrm{X}$ & $\mathrm{X} / \mathrm{X}$ \\
\hline 1 & $10 / 14$ & $22 / 41$ & $\mathrm{X} / \mathrm{X}$ \\
\hline 1.5 & $3.7 / 3.5$ & $\mathrm{X} / 27$ & $21 / \mathrm{X}$ \\
\hline 2 & $\mathrm{X} / \mathrm{X}$ & $\mathrm{X} / \mathrm{X}$ & $10 / \mathrm{X}$ \\
\hline
\end{tabular}

Finally, the autonomous sensor presented in section II was used. Fig. 13 shows the experimental setup with the autonomous sensor (top board) that includes the occupancy and belt detectors. Another ETRX-2 device was connected to the USB port of a PC in order to receive and process the transmitted data. As previewed in Table 4, the autonomous sensor correctly transmitted the data up to a distance of $2 \mathrm{~cm}$ for case 5 using a bridge rectifier. A larger distance was still possible, up to $2.5 \mathrm{~cm}$ because the autonomous sensor worked properly down to a voltage supply of $2 \mathrm{~V}$. However, efficiency decreased.

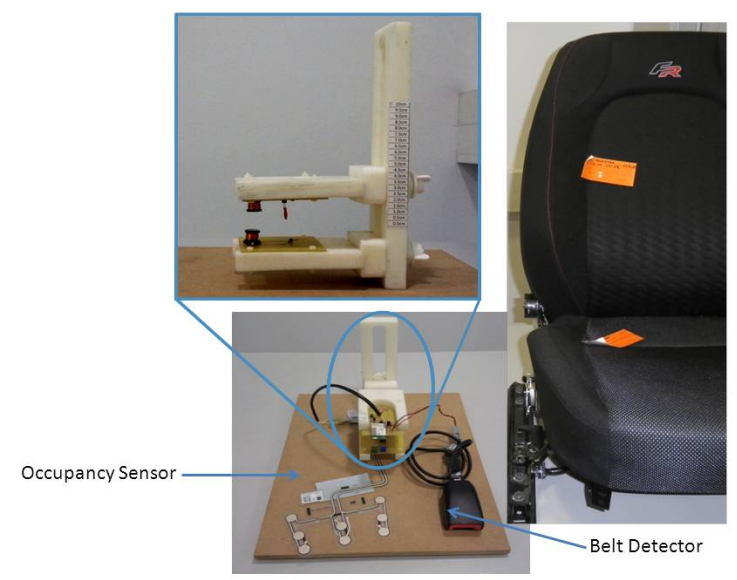

Fig. 13 Experimental setup. The left pictures show the mechanical setup with the primary (top board) and secondary (bottom board) networks. The left bottom picture shows the seat detectors which are connected to the autonomous sensor (top board). The right picture shows the vehicle seat. The occupancy sensor and the seat were provided by the car company SEAT.

\section{Conclusions}

This work proposes the use of inductive links for powering an autonomous sensor in charge of occupancy and belt detection in removable vehicle seats, where wiring the seat detectors from the vehicle chassis is unpractical. The autonomous sensor includes the seat detectors and a wireless transceiver to transfer the data about the state of the detectors. To drive the primary resonant network, a commercial class D amplifier has been used. A rather low frequency of operation $(<150 \mathrm{kHz})$ has been selected both to better comply with the ICNIRP regulations and to reduce the circuit complexity and power losses of the power amplifier. The selected application is spaceconstrained, so that small-size coils have to be used. Thus, ferrite-core coils have been selected against aircore coils as they lead to higher coupling and quality factors and higher coil values, which is beneficial to increase the transmitted power to the load. Commercial coils with values of $1 \mathrm{mH}$ and $10 \mathrm{mH}$ have been selected.

A rectifier and some kind of voltage regulation are required in the secondary network in order to conveniently power the autonomous sensor. Two different rectifiers have been considered: bridge and half-wave. Three types of voltage regulators have been analyzed: linear shunt and series regulators and buck switching converters. Their impact on the system power efficiency had been thoroughly assessed. Different combinations of coils $(1 \mathrm{mH}, 10 \mathrm{mH})$ and working frequencies $(40 \mathrm{kHz}, 120 \mathrm{kHz})$, resulting in five cases, have been assessed both by calculations and experimental results. For each of the cases, both bridge and half-wave rectifiers have been considered. At first, a load $\left(R_{\mathrm{L}}\right)$ of $100 \Omega$ has been used to emulate the autonomous sensor. Calculations and computed graphs show that operating points for the shunt regulator always lead to a lower equivalent load resistance $\left(R_{\text {Load }}\right)$ and, thus, to a higher power efficiency. Experimental tests have been carried out using a mechanical setup to fix the distance between the coils. Achieved power efficiencies range from around $50 \%$ to $10 \%$ for coil-to-coil distances from $0.5 \mathrm{~cm}$ to $2 \mathrm{~cm}$, respectively, which is remarkable considering the inner diameter of the coils, $0.6 \mathrm{~cm}$. Experimental tests also show that the autonomous sensor was properly powered up to coil distances of $2.5 \mathrm{~cm}$, i.e. more than four times the inner diameter of the coils. 


\section{References}

[1] B. Lenaerts, R. Puers, "Omnidirectional Inductive Powering for Biomedical Implants" Springer, 2009.

[2] A. K. RamRakhyani, S. Mirabbasi, and M. Chiao, "Design and Optimization of Resonance-Based Efficient Wireless Power Delivery Systems for Biomedical Implants," IEEE Transactions on Biomedical Circuits and Systems, vol. 5, no. 1, pp. 48-63, Feb. 2011.

[3] W.H. Ko, S.P. Liang, and C.D.F. Fung, "Design of radio-frequency powered coils for implant instruments," Medical and Biological Engineering and Computing, vol. 15, no. 6, pp. 634-640, 1977.

[4] D.M. Dobkin, The RF in RFID. Passive UFH RFID in Practice. Amsterdam: Newnes-Elsevier, 2008.

[5] L. Xun and S.Y. Hui, "Optimal Design of a Hybrid Winding Structure for Planar Contactless Battery Charging Platform," IEEE Transactions on Power Electronics, vol. 23, no. 1, pp. 455-463, Jan. 2008.

[6] S.Y.R. Hui and W.W.C. Ho, "A new generation of universal contactless Battery Charging platform for portable Consumer Electronic equipment," IEEE Transactions on Power Electronics, vol. 20, no. 3, pp. 620-627, May 2005.

[7] H.L. Li, A.P. Hu, G.A. Covic, "A Direct AC-AC Converter for Inductive Power-Transfer Systems," IEEE Transactions on Power Electronics, vol.27, no.2, pp.661-668, Feb. 2012.

[8] A. J. Moradewicz and M. P. Kazmierkowski, "Contactless Energy Transfer System With FPGAControlled Resonant Converter," IEEE Transactions on Industrial Electronics, vol.57, no.9, pp.3181-3190, Sept. 2010.

[9] S. Hasanzadeh, S. Vaez-Zadeh, A. H. Isfahani,"Optimization of a Contactless Power Transfer System for Electric Vehicles," IEEE Transactions on Vehicular Technology, vol. 61, no. 8, pp. 3566-3573, Oct. 2012.

[10] A. Khaligh, S. Dusmez, "Comprehensive Topological Analysis of Conductive and Inductive Charging Solutions for Plug-In Electric Vehicles," IEEE Transactions on Vehicular Technology, vol. 61, no. 8, pp. 3475-3489, Oct. 2012.
[11] ETV Corporation Pty Limited. Access date: August, 31. 2012. [Online]. Available: http://www.etv.com.au/

[12] R. Darraba, "A Movable or Removable Seat for a Motor Vehicle," World patent,WO2004/098943A1, Nov 18, 2004.

[13] J. Albesa, M. Gasulla, "Monitoring SwitchType Sensors via Inductive Coupling: Application to Occupancy and Belt Detection in Removable Vehicle Seats," IEEE Transactions on Power Electronics, vol. 27, no. 11, pp. 4472-4480, Nov. 2012.

[14] P.C. Crepaldi, T.C. Pimenta, R.L. Moreno, E.C. Rodriguez, "A Low Power CMOS Voltage Regulator for a Wireless Blood Pressure Biosensor," IEEE Transactions on Instrumentation and Measurement, vol. 61, no. 3, pp. 729-739, March 2012.

[15] R. Carta, M. Sfakiotakis, N. Pateromichelakis, J. Thoné, D.P. Tsakiris, R. Puers, "A multi-coil inductive powering system for an endoscopic capsule with vibratory actuation," Sensors and Actuators A, vol. 172, no. 1, pp. 253-258, Dec. 2011.

[16] J. Albesa; M. Gasulla, T. Jaeger, L.M. Reindl, "Wireless Power Transmission for Autonomous Sensors in Removable Vehicle Seats," in Proc. IEEE Vehicular Technology Conference, pp. 1-5, 5-8 Sept. 2011.

[17] J. Albesa; M. Gasulla, "Voltage regulation on inductive power links for autonomous sensors," in Proc. IEEE Instrumentation and Measurement Technology Conference, pp. 2678-2682, 13-16 May 2012.

[18] J. Albesa; L. Reindl; M. Gasulla, "Inductive power transmission for autonomous sensors: Voltage regulation effects on efficiency," in Proc. Systems, Signals \& Devices Multiconference, pp.16, 18-21 March 2013.

[19] C. Chih-Jung, C. Tah-Hsiung, L. Chih-Lung, and J. Zeui-Chown, "A Study of Loosely Coupled Coils for Wireless Power Transfer," IEEE Transactions on Circuits and Systems II: Express Briefs, vol. 57, no. 7, pp. 536-540, July 2010.

[20] A.P. Sample, D.A. Meyer, and J.R. Smith, "Analysis, Experimental Results, and Range Adaptation of Magnetically Coupled Resonators for Wireless Power Transfer," IEEE Transactions 
on Industrial Electronics, vol. 58, no. 2, pp. 544554, Feb. 2011.

[21] C.-S. Wang, G. A. Covic and O. H. Stielau, "Power transfer capability and bifurcation phenomena of loosely coupled inductive power transfer systems," IEEE Transactions on Industrial Electronics, vol. 51, no. 1, pp. 148-157, Feb. 2004.

[22] C. S. Wang, O. H. Stielau and G. A. Covic, "Design considerations for a contactless electric vehicle battery charger," IEEE Transactions on Industrial Electronics, vol. 52, no. 5, pp. 13081314, Oct. 2005.

[23] Li, H.L.; Hu, A.P.; Covic, G. A.; Tang, C.S., "Optimal coupling condition of IPT system for achieving maximum power transfer," Electronics Letters, vol. 45, no. 1, pp.76-77, Jan. 2009.

[24] International Comission on Non-Ionizing Radiation Protection (ICNIRP), "Guidelines for limiting Exposure to Time-Varying Electric, Magnetic, and Electro-Magnetic Fields (Up to 300 GHz," Health Physics, vol. 74, no. 4, pp. 494-522, 1998. [Online]. Available on: http://www.icnirp.de/documents/emfgdl.pdf.

[25] J. Albesa, M. Gasulla, "Inductive power transfer for autonomous sensors in presence of metallic structures," in Proc. IEEE Instrumentation and Measurement Technology Conference, pp. 664-669, 13-16 May 2012.
Joan Albesa received the B.Sc. and M.Sc. degrees in telecommunications and the Ph.D. degree from the

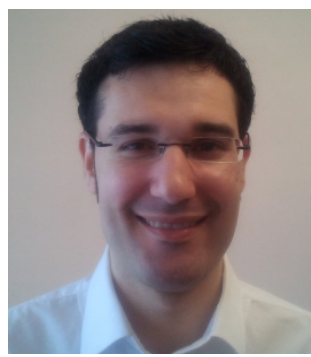
Universitat Politècnica de Catalunya (UPC), Barcelona, Spain, in 2005, 2007 and 2012 respectively. $\mathrm{He}$ is currently researcher at Laboratory for Electrical Instrumentation, Institute of Microsystem Technology (IMTEK), Albert Ludwigs University of Freiburg, Germany. His major research interests include energy harvesting, power conditioning, wireless power transfer and wireless sensor networks.

Manel Gasulla received the Enginyer (MEng) and

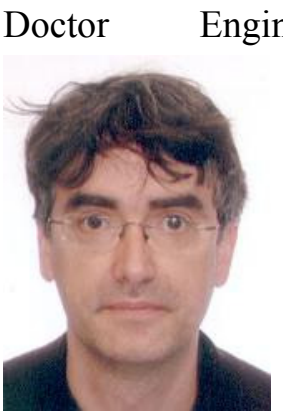
(PhD) degrees in Telecommunications from the Universitat Politècnica de Catalunya (UPC BarcelonaTech), Barcelona, in 1992 and 1999, respectively. Since 1993 he has been with the UPC, where he is an associate professor, engaged in teaching on Analog and Power Electronics and Electronic Instrumentation. In 2001-2002 he was a Visiting Postdoctoral Fellow at the Electronic Instrumentation Laboratory, Delft University of Technology, The Netherlands. His research interests include capacitive sensors, direct sensor-to-microcontroller interfaces, and energy harvesting and wireless power transfer circuits for autonomous sensors. He is co-author of more than 50 papers in journals and conferences, six Spanish patents, several chapters in books and the book Powering Autonomous Sensors (Springer, 2011). ORCID ID: 0000-0002-0364-6806. 